\title{
ASPECTOS DE UNA TEORÍA CONSTITUCIONAL PARA EUROPA
}

POR

\author{
PETER HÄBERLE
}

Bayreuth/St. Gallen

NOTA PRELIMINAR

Si queremos esbozar una teoría constitucional para Europa, tenemos que tener en cuenta que desde cada país se podrá aportar sólo una perspectiva. La que yo puedo dar es una "perspectiva alemana" que debe ser completada al menos con otras 24, de autores más jóvenes y mayores de los restantes Estados miembros de la Unión Europea. Sólo sobre el humus de un tal "contrato científico, social y generacional» podría un día establecerse un marco teórico amplio para todo y para todos. Es necesario un enfoque interdisciplinar en el sentido de unas más amplias y profundas "ciencias europeas" (en plural), por ejemplo, incorporando una historia del arte, la cultura, la música y la literatura europea, como he hecho yo personalmente en mi Memoria para la Universidad Húngaro-alemana en Budapest (1999). Finalmente, deberíamos permanecer siempre abiertos tanto desde el punto de vista teórico como desde el práctico a lo que venga desde Europa del Este, ya se trate de miembros de la Unión Europea, en cuanto Europa en sentido estricto, ya se trate de la Europa en sentido amplio del Consejo de Europa o de la Organización para la Seguridad y la Cooperación en Europa (actualmente con 46 y 55 miembros, respectivamente). Las fronteras entre ambas "Europas" son claramente abiertas y cambiantes. 


\section{PRIMERA PARTE: CUESTIONES METODOLÓGICAS}

Todo marco teórico tiene que revelar sus métodos, a ser posible, aunque habría que reconocer también que esa exigencia ha sido siempre una peculiaridad propia de la historia de la ciencia alemana. EI sano pragmatismo anglosajón y la penetrante y precisa dogmática francesa podrían también realizar aportaciones y correcciones.

\section{MÉTODOS DE TRABAJO CIENTÍFICO-CULTURALES ( «COMUNIDAD CONSTITUCIONAL" $Y$ "CONJUNTO DE CONSTITUCIONES PARCIALES»)}

La ciencia jurídica en general y la teoría de la Constitución en particular es un trabajo racional sobre textos escritos y no escritos, es "texto jurídico y ciencia cultural» y debe tomar conciencia de la "precomprensión" en el sentido de la hermenéutica de Schleiermacher a Gadamer. El trabajo en y sobre las constituciones está emparentado con los tres libros de las grandes religiones (la Tora, la Biblia y el Corán) en los que se sitúa el texto en el centro. Quizás la alta autoridad de las constituciones en la actualidad reciba aquí, en el fondo, una parte de su asombrosa legitimidad. La Constitución será concebida, a continuación, "como cultura» ("cultura constitucional», "cultura de los derechos fundamentales" son conceptos derivados). Las concepciones tradicionales de la Constitución mantienen su valor relativo (la Constitución como "impulso y límite», como "norma y tarea" como "organización de un proceso vital libre»), pero la perspectiva cultural (acompañada de la imagen de la Constitución como "contrato social») ocupa ahora el centro de nuestro campo visual. Desde esa perspectiva es preciso diferenciar también entre los textos constitucionales en sentido amplio, los textos clásicos desde Montesquieu hasta J. Rawls (teoría de la justicia), de H. P. Jonas (principio de responsabilidad) y G. Radbruch, y de los textos constitucionales en sentido estricto, los textos de las constituciones escritas y positivadas así como las sentencias directivas de los tribunales constitucionales. Para Europa son relevantes las declaraciones de W. Churchill a R. Schuman y J. Monnet, de A. de Gasperi a W. Hallstein y K. Adenauer. Así como nosotros debemos leer, en parte, la Constitución alemana con los ojos de Montesquieu, también debemos ver a Europa en sus textos jurídicos y su realidad constitucional "con los ojos" de los padres fundadores. Para ello debe quedar manifiesta la relevancia del contexto cultural, que resulta imprescindible en muchos textos $y$ del que se derivan también diferencias en cuanto al contenido. 
Una teoría constitucional para Europa debe descansar sobre la comprensión de que la Unión Europea es una "comunidad constitucional» (rescatamos aquí la feliz expresión de W. Hallstein de "comunidad europea") y requiere que se tenga en cuenta que Europa en sentido amplio es un conjunto de constituciones parciales: así, el Convenio Europeo de Derechos Humanos representa un nivel constitucional en Suiza y en Austria, aunque todavía no en Alemania. Europa procede, en su concepción, de la cultura, por importante que sea el mercado como vehículo de la integración (el mercado no es, sin embargo, un fin en sí mismo, ni es aceptable una "teología del mercado", sino que debe tener un significado instrumental). El irrenunciable sentimiento de "nosotros" de los ciudadanos europeos se origina y crece en complejos procesos de socialización cultural, en los que desarrollan también su efecto fuentes de consenso emocional (como, por ejemplo, el Himno europeo basado en Beethoven o la Bandera europea) y racional (como los textos de derechos fundamentales). La "identidad europea" tan buscada, sólo puede indagarse desde planteamientos científico-culturales y desde la complementariedad de la pluralidad de identidades nacionales. Desde esa perspectiva hay una cuota de utopía irrenunciable para cada poder constituyente (de lo que eran conscientes los padres fundadores). Los textos clásicos son aquí de aplicación, desde Kant hasta E. Bloch. El concepto de cultura, pluralista y abierto en el que nos basamos puede ser desarrollado con base en palabras clave tales como cultura popular, cultura alternativa y otros. El concepto de cultura procede, en definitiva, de un jurista, como Cicerón.

\section{PODER CONSTITUYENTE EN EUROPA: EN EL CAMINO DEL MÉTODO DE LA CONVENCIÓN}

Una teoría constitucional para Europa puede y debe evidenciar que se trata de "poder constituyente". Europa es ya apta para tener una Constitución y necesita una Constitución escrita. El paulatino proceso de constitucionalización de Europa, desarrollado durante años ha llegado hoy, por fortuna, a la fase del método convencional: los miembros de la Unión Europea ya no son los dueños de los Tratados sino que son sólo (con lo importante que eso es desde el punto de vista formal) actores en los procesos pluralistas del poder constituyente. La cercanía a los Estados Unidos en su formación histórica resulta evidente: se desarrolla aquí lo que en los años 1776, 1787 y 1791 se produjo. Los Federalist Papers son textos clásicos, textos constitucionales en sentido amplio. Por supuesto que es necesaria todavía una democratización y parlamentarización más amplia del poder constituyente en la Unión Eu- 
ropea, pero el proyecto de Junio/octubre de 2004 ha aportado claros progresos: sus temas, contenidos y avances son de "naturaleza constitucional», lo que quiere decir: fundamental, de carácter fundador de la «res publica europea».

\section{APERTURA Y CARÁCTER PÚBLICO DEL PROCESO DE CONSTITUCIONALIZACIÓN DE EUROPA: ESPACIO PÚBLICO EUROPEO DESDE LA CULTURA Y EL ARTE, INCREMENTADO TAMBIÉN DESDE INTERNET Y DESDE LA POLÍTICA (CONSTITUCIONAL)}

Hay un espacio público europeo desde hace mucho tiempo en la cultura y el arte (desde el Renacimiento pasando por la Reforma hasta la llustración, tangible en las obras de los grandes poetas, filósofos, músicos, pintores y escultores). Ante todo, el espacio público europeo se despliega también en el ámbito de la política, evidenciado en las manifestaciones que superan las fronteras, en los medios de comunicación y su "opinión pública», en la publicidad de las sesiones del Parlamento Europeo y de las decisiones de los tribunales. Una parte del carácter público de la constitución europea se manifiesta en la resonancia que ha tenido, no sólo en internet, el trabajo de la Convención Europea. También hay que mencionar aquí algunos proyectos constitucionales particulares (tales como el de Schwarze/Flauss), pero también memoriales, peticiones y trabajos científicos. Ciertamente, el espacio público europeo tiene también déficits, acaso en la forma en que las elecciones al parlamento europeo de 2004 se han desarrollado, con una atención mayor hacia los temas nacionales que hacia los europeos. Los partidos políticos tendrían que actuar más a nivel europeo. El proyecto constitucional de junio de 2004 exige a la legislación, con razón, publicidad. Desde el punto de vista teórico, este principio de publicidad deriva de trabajos de autores tales como I. Kant, R. Smend y J. Habermas.

\section{PROCESO DE PRODUCCIÓN Y RECEPCIÓN REGIONAL Y MUNDIAL (LA TRÍADA DE TEXTOS, TEORÍAS Y JURISPRUDENCIA, EL DERECHO COMPARADO COMO «QUINTO» MÉTODO DE INTERPRETACIÓN, EL «DERECHO CONSTITUCIONAL COMÚN EUROPEO»)}

El trabajo sobre las constituciones, político-constitucional o de naturaleza interpretativa, está caracterizado hoy por los procesos de producción y recepción. Se trata de la tríada de textos, teorías y jurispru- 
dencia. En el ámbito regional (por ejemplo, en Europa) y mundial (vía internet) se están produciendo procesos de ósmosis, de recepción más o menos consciente, y también de avances creativos. Las influencias recíprocas de los europeos, también en el plano nacional, son verificables en todas partes. Instrumentos de recepción son los partidos políticos, los medios de comunicación, pero también y no en último lugar, los científicos. También entre las naciones tienen lugar efectos recíprocos asombrosos y procesos de intercambio. Los procesos de recepción en Europa del Este son hoy evidentes, ante todo en el campo de los derechos fundamentales, ya que la jurisprudencia del Tribunal Constitucional Federal alemán se ha difundido a lo largo de Europa. La "devolución de poderes" en Inglaterra encuentra también apoyo seguro en el material textual que se ha originado en el ámbito europeo desde hace mucho tiempo. Se deben evitar, en definitiva, calles de una sola dirección. Debería tratarse de procesos de aprendizaje recíprocos; por ejemplo, la fórmula húngara de las minorías como "factores de formación del Estado" merece atención no sólo en el este de Europa. Estados candidatos como Croacia o Rumania deberían tenerla en cuenta.

Un instrumento científico en todos estos procesos es la teoría desarrollada por el autor en 1989 del Derecho comparado como "quinto" método de interpretación (junto a los cuatro clásicos de Savigny, ahora también asumida por el Tribunal Constitucional de Liechtenstein), así como la figura propuesta en 1983/1991, también por el autor del "derecho constitucional común europeo" y la del "paradigma de la evolución gradual de los textos" (1989), que hoy la realidad constitucional nos trae en forma de nuevos textos constitucionales.

\section{LA TEORÍA CONSTITUCIONAL EUROPEA COMO DISCIPLINA PROPIA (LA DESPEDIDA DEL «DERECHO COMUNITARIO»)}

Comenzando en 1999 y posteriormente en una monografía del mismo nombre de 2001/2002 (tercera edición de 2005), la «teoría constitucional europea" intenta promover el foro científico en el que tiene que asentarse una teoría constitucional para Europa. Actualmente tenemos "derecho constitucional europeo", "derecho administrativo europeo", "derecho civil y penal europeo", etc. Pero no hay ya un "derecho comunitario europeo" delimitable, pese a que en muchos manuales y comentarios se siga utilizando este término. El «derecho comunitario europeo" fue de gran ayuda como expediente provisional para los comienzos. Pero con Maastricht y Amsterdam, Niza y Bruselas, se han constituido ya la disciplinas particulares. De acuerdo con su propia concepción, el proyecto de Constitución de junio de 2004 es, en muchos artículos (con la excepción de los artículos 437-445) una «Cons- 
titución», no un "Tratado». Por sus temas y su contenidos, su sistemática y su forma, se trata de una "Constitución parcial» en el sentido antes mencionado.

\section{SEGUNDA PARTE: CONTENIDOS (SELECCIÓN)}

Las palabras clave en relación con el contenido de una teoría constitucional para Europa se manifiestan ya en parte en los métodos, en cuanto métodos y contenidos no se pueden separar de una manera clara. No obstante, vamos a hacer algunas referencias materiales a los principios constitucionales de Europa, aunque sea de manera fragmentaria, por motivos de tiempo.

\section{1. "LA IDENTIDAD EUROPEA", "LAS IDENTIDADES NACIONALES" $Y$ EL "DERECHO CONSTITUCIONAL EUROPEO NACIONAL"}

La cuestión de las identidades se introduce ya en nuestro campo visual. No podrían definirse desde un punto de vista jurídico en sentido estricto, si bien el "derecho" debe analizarse a menudo con una perspectiva amplia que incluya los aspectos culturales. En última instancia, el concepto de identidad se remonta al sistema filosófico, en el contexto jurídico debe bastar la advertencia de que se trata de una figura jurídica manejable pero que no debe utilizarse de una manera excesiva. "La identidad europea" describe el conjunto de la cultura jurídica europea, como los principios de "derecho constitucional común europeo" (dignidad humana, división de poderes horizontal y vertical, neutralidad ideológica del Estado, derechos humanos, protección de las minorías, democracia pluralista e independencia judicial, principios tangibles, en parte, en los criterios de Copenhague; también la metodología jurídica y científica se integra aquí). La atención debe dirigirse en dirección a la historia cultural europea y a sus grandes creaciones. Una referencia geográfica es inevitable. El norte de África puede ser objeto de asociación a través del proceso de Barcelona, pero no es una parte de Europa (a pesar de la herencia árabe). La entrada de Turquía en la Unión Europea está sometida a prueba actualmente. Hay límites culturales al crecimiento de Europa. En abstracto se puede afirmar que los factores históricos, culturales, geográficos y económicos contribuyen de manera conjunta a crear la «identidad europea». Las delimitaciones (en relación con Asia y África) son imprescindibles, al tiempo que es necesario construir "puentes" hacia USA y Latinoamérica. 
La «identidad nacional» es el concepto asociado al de la identidad europea. Europa vive de la pluralidad de sus naciones, con sus pasos fronterizos, pese a que, desde "Schengen" muchos estados europeos ya no son "extranjeros" y a que la teoría de los tres elementos del Estado de G. Jellinek debe ser revisada, por ejemplo, incorporando la cultura como "cuarto", si no como el primer elemento del Estado. Singularidades de las culturas jurídicas nacionales son muchas figuras, como el Consejo de Estado francés en el ámbito del Derecho administrativo, el derecho parlamentario inglés o la casi "perfecta" comunidad de derechos fundamentales en Alemania. De gran trascendencia para la "identidad nacional» de Italia son nombres como los de Dante o Verdi, del mismo modo que lo es para Francia su espíritu republicano, o para España el Siglo de Oro, o la Constitución de 1791 para Polonia. También los traumas históricos y las heridas forman parte de ese cuadro: "Chernobil» se menciona, no sin sentido, en un artículo de la Constitución de Ucrania de 1996 (art. 16).

Un puente entre la identidad europea y las identidades nacionales se intenta establecer con mi planteamiento sobre el "derecho constitucional europeo nacional» (1995). En este concepto se integran los artículos sobre Europa de las constituciones nacionales, tales como el artículo 23 de la Constitución alemana o el artículo 54.1 de la Constitución de Berna (1993). España se esfuerza actualmente en las reformas constitucionales proyectadas por incorporar un artículo sobre Europa, como también Italia. Se trata de referencias textuales a la integración de Europa, lo que es posible a través de diversas fórmulas: referencias al Convenio Europeo de Derechos Humanos, a la cooperación regional en Europa, a las instituciones de la Unión Europea, a la formación de una comunidad europea en su conjunto, así como a los valores fundamentales de Europa. Yo he recomendado para España estos artículos sobre Europa. En ellos se expresa, por un lado, la "europeización» intensiva de las constituciones nacionales, mientras que por otro se interioriza en cada Nación a Europa, lo que quiere decir que la Nación permanece, pero se enriquece con "Europa».

\section{LOS PREÁMBULOS COMO FIGURA CULTURAL, CIENTÍFICA, LITERARIA Y CONSTITUCIONAL. LA FORMACIÓN DE LOS TEXTOS CERCANA A LOS CIUDADANOS}

Una teoría constitucional para Europa debe tener en cuenta el específico "potencial» de los Preámbulos. Ensayados previamente en el ámbito interno de los Estados (también utilizados en el Derecho inter- 
nacional) los Preámbulos proporcionan mucho: se parecen, desde el punto de vista cultural, a los Prólogos, las Oberturas y los Preludios, incorporan un concentrado de la Constitución y favorecen su conocimiento y comprensión, reelaboran la dimensión temporal (el patrimonio cultural y, en su caso, el desarrollo utópico de futuro) y pueden desplegar una fuerza normativa de carácter irradiante. Si se formulan con un significado que resulte próximo a los ciudadanos contribuyen a atraerlos y "ganarlos". Tanto la Carta de Derechos Fundamentales de la Unión Europea, como el proyecto de Constitución de 2004 se sirven de la forma artística del Preámbulo. En el último caso resulta molesto, tan sólo, la fatua cláusula de agradecimiento del párrafo 6 , que no tiene parangón en el mundo en el derecho constitucional comparado (¿un producto de Giscard y Fischer?). Una teoría europea de los preámbulos elaborada, como la existente, es piedra angular de una teoría constitucional para Europa.

\section{LA CARTA DE DERECHOS FUNDAMENTALES DE LA UNIÓN EUROPEA}

La Carta es un sillar central para la teoría constitucional europea. En sus soluciones inteligentes y pragmáticas, en su elaboración creativa desde los estándares usuales en el derecho comparado europeo en el tiempo y el espacio, en sus innovaciones y su preservación de aquello que ya está acreditado, se puede considerar como una pieza afortunada de la cultura jurídica común europea.

\section{VALORES FUNDAMENTALES Y OBJETIVOS DE LA UNIÓN}

El proyecto constitucional de junio/octubre de 2004 incorpora nuevos desarrollos en esta materia. Baste mencionar aquí la referencia a la Unión como comunidad de Derecho (W. Hallstein), de paz, de protección del medio ambiente y de solidaridad, así como (no en último lugar) de cultura. Las cláusulas relativas a los valores están muy entrelazadas con los textos relativos a los derechos fundamentales: los derechos fundamentales son, a su vez, valores fundamentales, que desarrollan su eficacia en el proceso interpretativo de los políticos y los juristas. En estos preceptos del proyecto constitucional se ha realizado, en $\mathrm{mi}$ opinión, un buen trabajo. Especialmente destacable es la nueva política de vecindad con los países del entorno. 


\section{EL TRIBUNAL DE JUSTICIA Y EL TRIBUNAL EUROPEO DE DERECHOS HUMANOS COMO "TRIBUNALES CONSTITUCIONALES" (LA SOCIEDAD ABIERTA DE LOS INTÉRPRETES CONSTITUCIONALES COMO «DEFENSORES»DE LA CONSTITUCIÓN)}

Resulta evidente que el Tribunal de Justicia y el Tribunal Europeo de Derechos Humanos son "tribunales constitucionales", aunque sólo tengan competencias en relación con "constituciones parciales" si bien, por lo demás, con todos los rasgos materiales y formales que son característicos de los tribunales constitucionales. Estos tribunales son "defensores" de la Constitución parcial europea, aunque no lo sean ellos solos por cuanto, en última instancia, cada ciudadano europeo es defensor de la Constitución (como nos enseña la tesis del autor de este trabajo sobre la sociedad abierta de los intérpretes constitucionales).

\section{LUCES Y SOMBRAS DEL PROYECTO CONSTITUCIONAL DE 2004 (CONTINUIDAD, DESARROLLOS, DÉFICITS)}

Una teoría constitucional para Europa debe estar en situación de valorar tanto las luces como las sombras de los textos. Un "Coro" de múltiples voces debe ser oído en la casa europea. Desde mi perspectiva, quisiera mencionar ahora sólo algunas cuestiones clave: el déficit democrático permanece; no hay, desgraciadamente, un referéndum de ámbito europeo para ratificación de la Constitución europea (la democracia participativa sigue siendo puntual: iniciativa legislativa de los ciudadanos), la proximidad a los ciudadanos y la transparencia se ha conseguido sólo en parte, acaso en el Preámbulo y en los artículos dedicados a los derechos fundamentales y a los valores. El conjunto expresa más bien una "continuidad" en lo ya acreditado, en parte un desarrollo acertado y un compromiso arduo. Puede ser que el texto tarde mucho en ser una realidad constitucional europea. ¿Podría compararse este proyecto con los clásicos Federalist Papers de los Estados Unidos?

\section{PERSPECTIVAS Y CONCLUSIÓN}

Europa sigue siendo un proyecto abierto con "finalidad" abierta. Los científicos europeos pueden aportar algo, en ese sentido, contribuyendo a que se tome conciencia de las oportunidades y los límites del proceso de constitucionalización. La casa europea tiene muchas 
viviendas, en una de las cuales trabajamos los científicos. En última instancia, se trata de los ciudadanos («Europa de los ciudadanos»). Ellos tienen que adquirir confianza en la Constitución a través de una pedagogía intensa de las instituciones europeas. Esto requiere un esfuerzo continuado de todos los días, un desarrollo del espacio público europeo y también para el futuro una "cuota de utopía" (por ejemplo, la idea de un contrato social europeo) como la que tenían y nos han legado los padres fundadores.

\section{REFERENCIA BIBLIOGRÁFICA}

H. Dreier (Hrsg.), Grundgesetz-Kommentar, Bd. I, 2. Aufl. 2004.

J. A. Frowein/W. Peukert, Europäische Menschenrechtskonvention, 2. Aufl. 1996.

P. HÄBERLE, Verfassungslehre als Kulturwissenschaft, 1. Aufl. 1982, 2. Aufl. 1998.

P. HÄBERLE, Europäische Verfassungslehre, 2. Aufl. 2004 (3. Aufl. 2005).

K. HESSE, Grundzüge des Verfassungsrechts der Bundesrepublik Deutschland, 20. Aufl. 1999.

M. KotZUR, Grenznachbarschaftliche Zusammenarbeit in Europa, 2004.

H. Roggemann (Hrsg.), Die Verfassungen Mittel- und Osteuropas, 1999. 